\title{
Exploring Futuring and Predictive Analytics for Developing Organizational Strategy
}

Victor Alan Starns, Colorado Technical University, USA

\begin{abstract}
The study addresses the type of leadership styles that promote Innovation, transformational, and adaptive leadership - in this study of futuring, discussing the evolving role of the futurist within the organization. The discussion of the history of futurists within the organization for the public and private sectors looks at the part of the futurist to determine the relevance of today compared to 20 years ago. Also, it looks at how the futurist can utilize the futurist's techniques in their organization. The study of predictive analytics addresses the use of predictive analytics with examples of companies that use predictive analytics, and the reasons they use predictive analytics-examining predictive analytics to determine if they are driving more informed business decisions. The article explores the relationship between big data and predictive analytics and if big data is responsible for the popularity of predictive analytics.
\end{abstract}

\section{KEYWORDS}

Adaptive Leadership, Futuring, Organizational Strategy, Predictive Analytics, Transformational Leadership

\section{INTRODUCTION}

In a vibrant, unstable, and complicated business environment, organizations are forced to use the most accurate information and knowledge available, not only in the present but into the future, to assess and predict the external and internal environments for making strategic, operational, and tactical decisions (Shujahat, Hussain, Javed, Malik, Thurasamy, \& Ali, 2017). The future will not arrive entirely shaped but emerges in a step by step method (Webb, 2016). Academics and business leaders are seeking the next big strategic move to enhance their competitive edge (Siegel, 2016). Millett (2006) remarked that providing direction into the future is the responsibility of Leadership. Decisions made based on information and knowledge resources can result in a competitive advantage (Shujahat et al., 2017). A critical role of Leadership is to provide direction into the future. In the world of companies, organizations, and governments, the executive leader is one who plays the principal part in defining the mission, setting the goals, developing a vision, and making plans that move beyond the familiar of today to the uncertainties of tomorrow (Ag Budin \& Wafa, 2015).

This study looks at two different processes that organizations can use to develop strategic planning into the future. The first process is called futuring. In the management environment, futuring merges useful history with methods from science, mathematics, and system analytics to structure 
well-thought-out opportunities for the future (Millet, 2011). Webb (2016) exclaimed that the future might first materialize as arbitrary ideas at the fringe of society, but never in the mainstream. Crews (2017) remarked that the future is not factual and hard to predict.

Millet (2011) describes futuring as a process that helps us make decisions today that will have positive long-term effects. In the aspect of a business, futuring is a characteristic of due diligence and risk management. Normative scenarios generate lively descriptions of desired futures (Crews, 2017). Smith (2015) explained the role of the futurists as evolving inside companies to help predict the desired future of the organization created on methodical procedures involving group action and collaboration. Crews (2017) stated that trends might offer and an indication of the direction the future is moving. Let us move on to the second process of Predictive Analytics.

Iovan (2017) asserted that Predictive Analytics gives organizations a way to generate decisions based on precise information at the correct time by developing systems that are capable of converting collected data information to produce actions that directly benefit the organization. Companies that have embraced predictive analytics have been able to leverage the data into useful knowledge that enables them to save money and improve operations across many areas of their companies (Siegel, 2016). The use of information to enhance decision-making and motivate innovation, converting information to knowledge. Predictive analytics is an excellent way to convert information into knowledge (Hair, 2007). The goal of predictive analytics is to support the decision-making process by identifying patterns and emphasizing valuable information (Fadairo, Williams, \& Maggio, 2015).

\section{Leadership Style or Styles Better Foster a Culture of Innovation}

CEO leadership style plays an essential role in promoting organizational innovation. The introduction of supportive practices within the organization will influence the innovative capability and behavior of the individuals in the organization (Ag Budin \& Wafa, 2015). Even though not directly immersed in the development of organizational innovation, the CEO must creäte a climate that favors experimentation and initiation of new ideas, procedures, or structures. The CEO's leadership style must promote Innovation (Prasad \& Junni, 2016). Lewis (2013) states that Leadership is not a position but a behavior. It is the act of influencing people to follow their lead. It is not a personal attribute that makes an individual a leader. Being a leader is the ability to behave differently as the situation required. Innovative organizations will have a transformational leader.

\section{Transformational Leadership}

Transformational leaders not only have a clear vision, but they also communicate the vision to the employees in an effective manner. The transformational leader acts as a role model to the organization and inspires the workers to put the good of the company above self (Salem, 2015). A transformational leader has a style that gives both the leader and followers inspiration to motivate each other. The leader must emit and inspire all employees to be transformational leaders (Mozammel \& Haan, 2016). The leader encourages the employees to be innovative; the leader will take personal risks without fear of using unconventional approaches to achieve the organizational goals (Salem, 2015). The leaders influence workers to the conscience of essential matters that will allow them to develop a new perspective on challenging problems. Employee engagement will be higher with transformational Leadership (Mozammel \& Haan, 2016). One highly effective style of transformational Leadership is Adaptive Leadership.

\section{Adaptive Leadership}

Adaptive Leadership emphasizes the behaviors of the leader relative to the tasks of followers in the situations in which they find themselves. Adaptive Leadership inspires actual change across numerous levels of self, organization, and community (Northouse, 2016). Leadership is a universal social occurrence. Management affects not only the company's but also every characteristic of human action (Amar \& Hlupic, 2016). The Adaptive Leader description and operation mentality that prevail 
in theories and practices of Change Leadership are no longer applicable in conditions of diversity evident by volatility, uncertainty, complexity, and ambiguity (Bushe \& Marshak, 2016).

In the past, companies that have experienced success, developing a distinctive way of regarding the humanity and behavior models. As a product of prior learning that has now become internalized and turn into part of the leadership culture. When circumstances change, the leadership culture turns into a hidden obstacle to strategic change; the leaders continue to comprehend the company circumstances as the usual occurrences (Hurtado \& Mukherji, 2015). In the knowledge obsessed modern economy, company expansion comes from innovation instead of operational productivity. This change has generated the significance of human component in work, explicit knowledge, the most critical influence of creation, exist in the human mind (Amar \& Hlupic, 2016).

\section{FUTURING}

\section{The Evolving Role of the Futurist}

Companies that focus on the future emphasize the action of bringing new creations into the market and opens limitless opportunities for growth. Business leaders must be proactive and goal-oriented in their assessments while being concerned about current problems and operations (Anonymous, 2001). In the fast-moving modern society, technology, and globalization, businesses require far-reaching and creative methods that will motivate and predict the company's future knowledge (Smith, 2015). Leaders must be able to manage the current day to day activities while creating a future vision of how the company will evolve. If the intention for the company growth, the commitment to scanning the possibilities, advocating innovation, developing high performing motivation systems, empowering employees to do extraordinary work, continuous improvement, and nurturing synergetic relationships. The creation of a futurist will be required to accomplish these goals (Anonymous, 2001).

The futurist will start by looking at global and national concerns, economics, world events, public policy and regulations, social and demographic trends, consumer behavior, market dynamics, and competition (Millett, 2006). The role of the futurist is evolving within organizations by helping the organization improve the projection of the desired future based on methodical procedures (Smith, 20150. The futurist is an individual that looks at problems from the external environment in a macroscopic viewpoint and the internal atmosphere from a microscopic perspective and uses both to think through a problem that the company faces (Millett, 2006).

Leaders that embrace and learn the futuring processes that observe significant changing patterns in the environment can help employees prepare for the future of work and life changes (Chong, 1996). Futuring looks at the people that buy and consume the products or services the company offers and looks at the world the consumer lives. With the understanding of various trends and the probable products or services, upper management can deduce outcomes from the future external environment that the company may encounter (Millett, 2006). The surveying of historical trends combined with subject matter experts, futuring with expansion as it continues to enhance the market success and improves the core competencies in both public and private relevance (Smith, 2015). The futurist takes into consideration the organization's mission, goals, assets, and culture and carefully examines the significance as they relate to external trends (Millet, 2006). Futuring is a management framework merges applied history with other approaches adapted from science, mathematics, and systems analysis to structure well-considered opportunities for the future. The futuring process helps the company in making decisions in the present-day that will have positive long-term results. Futuring is a combination of due diligence and risk management (Millet, 2011).

\section{History of the Futurist in the Organization}

Futuring began and was first put into practice in the 1920s during World War I stemmed from strategic planning. Many of the conventions of futuring and strategic planning are the same (Smith, 2015). 
The exploration of the role of the organizational futurist began when people started to examine the difficulty that companies experienced when they tried to use foresight work (Hines \& Gold, 2014). The futurist acknowledged that the future world is continuous with the current world. By looking at what is systematically taking place in the modern world, we could learn a lot about what may take place in the future (Anonymous, 2004). The futurist is not interested in sudden developments or oneday occurrences but looks at trends like shifts in population, land use, technology, and government policy (Smith, 2015).

Millet (2011) states that history will furnish indicators of the future. When companies identify the historical trends or patterns within the company that has held a long-term consistency in the cultural behavior, even if history does not repeat itself, certain cultural behaviors will. The ability to spot repetitions of traditions, customs, laws, and memes can help us to determine the things that hinder growth or create growth. Webb (2016) believes that trends can be slow to develop and misunderstanding of the long-term potential. Trends can help us to recognize changes that are crucial to the survival of a company. Millet (2011) states that the past shows examples of future behavior. Understanding why things happened in the past gives foresight into what may happen in the future.

Futuring has changed the consulting industry from subject matter experts, doctor-patient, to using appreciative inquiry (A.I.) (Watkins, Mohr, \& Kelly, 2011). A.I. is a process that looks at the positive aspect of the company-looking at what works well for building changes based on the positive characteristics of the company, instead of fixing problems, eliminating problems by taking different actions to reach the desired future (Faure, 2006). Companies have also embraced the process of action research (A.R.). A.R. is a systematic process of cycles of inquiry or investigation that enables groups to understand the nature of challenging events or phenomena. The character of A.I. is the focus on problems investigated in a systematic process of inquiry. The development of explanations or knowledge in each cycle leads to a better understanding of the current reality and the steps to the desired future (Stringer, 2014).

\section{Importance of the Futurist}

Research has shown that the role of the futurist is more critical today than it has been in the last 20 years. The need for futuring has increased considerably. The beginning of futuring may not have been intentional, but the desire for it has grown from necessity, much like strategic planning (Smith, 2015). Valikangas, Gibbert, Nair, Pukka, \& Peixoto (2016) states that futurists, managers, and academics search for novelty, foresight, and what is next. When novelty becomes the norm, it is no longer new, and something else is out there that will rock the industry. Apple was an excellent example of a company that changed the way people listen to music. Not everyone in the organization is a futurist. Companies can spot the people that are innovators and first adopters and use them to identify the outliers.

Amy Webb (2017), a celebrated futurist, talks about the companies that are on the fringes that are disrupting the mainstream industries. The fast-changing technology allows us to integrate faster and bring the future into our businesses at an alarming rate. In the steel fabrication industry, computeroperated machinery has revolutionized the industry. The companies that refuse to adopt the new technology can no longer compete, and the smaller companies that embraced technology have taken over the industry. The futurist can help new startup companies find fringe technology. As Valikangas et al. (2016) states, smaller companies punch above their weight by using fringe technology instead of investing in costly mainstream resources. The 3D printer is an example of an outlier that is rapidly moving into the mainstream.

Many companies are forming integrated product/program teams (IPT) to use futuring to enhance their capabilities of finding and implementing new technologies, materials, services, and suppliers that are on the fringes. These IPT teams are people from all parts of the organization; they are the people that are willing to try new things, new scenarios and find ways to implement them into the company (Kerzner, 2013). Futurists are becoming an essential part of a company's strategic management team, 
either as a consultant or a hired employee. People with futuring skills will be part of all companies, either large or small (Webb, 2017).

\section{How Organizations Might Use a Futurist}

One of the futuring techniques that work well with teams is scenario planning to help companies identify opportunities and threats (Wade, 2012). The use of scenario planning in the project management field for risk management. The project team does a best-case scenario and a worstcase scenario to determine the real risks that need to be accepted or mitigated. We also plan on how to exploit chance in a best-case scenario (Kerzner, 2013). Scenario planning can help to identify the direction that a company can move to reach the desired future. Exxon was able to avoid heavy losses and cope with the oil embargo by doing scenario planning concerning OPEC in the middle 1970s (Millet, 2011).

Delphi Methodology is a method used to gather information used to reach a consensus of subject matter experts on a subject. The Delphi method can be done by using a questionnaire or by meeting in a group setting like a think tank. It was using the Delphi method to reduce bias and to keep one person or a group from having undue influence (Project Management Institute, 2017). Visioning is also a futuring technique that works well for companies trying to decide on the desired future and is not sure how the future may look. Many times, companies are stuck in everyday problems, and changing the future is not on the menu. An outside consultant can do visioning; an appreciative inquiry process may help to show the group the core competencies of the company (Wade, 2012).

Hiring a consulting firm that specializes in trends specific to the industry will help to achieve visioning. An outside consultant can bring new energy into the upper management and show them a vision of the future (Stringer, 2014). Brainstorming is a process of data collection by using a small team, group, or subject matter experts to identify risks, ideas, or solutions. Brainstorming is effective in futuring, utilizing many different groups from anywhere in the organization (Project Management Institute, 2017).

\section{PREDICTIVE ANALYTICS}

\section{Common Uses for Predictive Analytics}

The basis of building a prosperous and sustainable business is producing the products, selling, or providing services that the customers want. A customer must provide value-added features with a correct price to draw customers and maximize profits (Asthana, 2006). Businesses often view data mining and predictive analytics as to the same process. Data mining and predictive analytics are interacting but separate processes. The data mining process first searches for patterns in data such as numbers, text or words and phrases, click and time spent patterns or web movements, and visual images. The data mining process allows predictive analytics to use the established correlations to predict future events, trends, and behavioral patterns (Hair, 2007).

The amount of risk and a large volume of data the financial industry has adopted predictive analytics for the detection and reduction fraud, determine credit risk, expand cross-sell and upsell prospects and customer retention (SAS, 2017). Many retail stores and supermarkets rely on predictive analytics to price their products to capitalize on the price that customers in certain areas will pay for the product. Predictive analytics can give a company a competitive edge by allowing them to lower or raise the price of a product and adjust inventories to use just-in-time methods lowering costs (Asthana, 2006). Conducting a predictive analytics study, and the results showed that men who go to the store to buy diapers would also buy beer on the same visit. Retailers are using predictive analytics to determine which products to stock and when to use promotional events that offer customers the most suitable products and determine which products to discontinue and use valuable retail space effectively (SAS, 2017). 
E-commerce has become involved in predictive analytics from the start. Online businesses have the means to record and store tons of data that can mine for use. The e-commerce business has expanded to the numbers that have crippled the brick and mortar stores in many areas that involve the use of predictive analytics (Siegel, 2016). Predictive analytics can be used by companies to search for companies that are on the cutting edge of technology and predict which companies to invest in or buy. Finding the outlier companies could be the answer for a mature company to embrace technology that could put them back as a leader in a new industry, therefore ensuring sustainability (Valikangas, et el, 2016). Companies are using predictive analytics to determine the probability of equipment failures and future resource requirements, mitigating safety and risks, performance improvements. The health and insurance business has turned to predictive analytics to determine the possibility of chronic illnesses and deaths. Predictive analytics is used by manufacturing companies to forecast future production or new products (SAS, 2017).

\section{Examples and Reasons Companies Use Predictive Analytics}

Companies that have embraced predictive analytics have been able to leverage the data into useful knowledge that enables them to save money and improve operations across many areas of their companies (Siegel, 2016). General Motors has used predictive analytics to create successful strategies for better customer service. General motors have over 12 million credit card customers in a large database that contains detailed information on customer spending habits. For each customer in the database, General Motors has an average of 20 pieces of information to help them predict the future (Hair, 2007). The second-largest public power utility company in the United States is the Salt River Project; they also are the largest water supplier in Arizona. Salt River Project uses sensor data analysis to predict the maintenance needs of their power-generating turbines (SAS, 2017).

Walmart has been able to use predictive analytics and information technology to collect and mine an extreme amount of purchase data. The data shows information about customer's preferences, preferred brands, view of the purchase price. Walmart uses this information to enhance operations throughout its entire value chain, increasing their competitive advantage (Asthana, 2006). Nokia was able to use predictive analytics to examine six billion data points from a customer survey that helped them develop the Nseries brand multimedia do-it-all phones. Vodafone use of predictive analytics allows them to examine over 20 predictive models per month. Vodafone can improve their understanding of the telecommunications industry and predict future developments in the marketplace (Hair, 2007).

The use of predictive analytics has allowed Amazon.com to claim that product recommendations account for 35 percent of their online sales. Amazon has also used anticipatory shipping that places items at key delivery centers before ordering, reducing delays between customers ordering, and receiving products (Siegel, 2016). Lenovo, a manufacturer of computers, has used predictive analytics to improve warranty claims. This project has reduced warranty costs by $10-15$ percent (SAS, 2017). By using predictive analytics, Target has been able to increase revenues by 15 to 20 percent by direct mail targeting using product choice models (Siegel, 2016).

\section{Predictive Analytics Driving Informed Decisions}

Information is the foundation of innovation in a knowledge-centered economy. The use of information to enhance decision-making and motivate innovation, converting information to knowledge. Predictive analytics is an excellent way to convert information into knowledge (Hair, 2007). Predictive analytics is having an expanding influence on decision making and performance within many companies (Liberatore, Pollack-Johnson, \& Clain, 2017). The growing use of data-driven decision making has many businesses turning to predictive analytics software and services. The implementation of predictive analysis has allowed large companies and government agencies to make better decisions concerning operational efficiency 
regarding cost, productivity, and innovation. The goal of predictive analytics is to support the decision-making process by identifying patterns and emphasizing valuable information (Fadairo, Williams, \& Maggio, 2015).

Companies are continuing to use complex analytical processes with increasing access to useful data. There is a disparity in the company's ability to produce analytical results and the ability to implement them effectively into business concerns (Ransbotham, Kiron, \& Prentice, 2015). The decision models produced by predictive analytics describes the correlation between all factors of the decision. The model includes all variables known about the data relationships, the decision, and predicted results of the decision. The goal is to predict the outcome of decisions that contain multiple variables accurately. The model design allows the company to maximize certain results while minimizing others, giving the best decision for the situation (Hair, 2007).

As the data-driven business environment increases, forcing high-level Leadership to make decisions based on predictive analytics that uses methods that they do not entirely comprehend (Ransbotham, Kiron, \& Prentice, 2015). The implementation of predictive analytics allows data analysts to help companies solve problems or pursue opportunities and recognize relationships as they presently exist or expected to exist in the future. The models created using predictive analytics, used in the creation of knowledge, but to correctly utilize the knowledge generated by predictive analytics, it will require a highly trained expert (Hair, 2007).

\section{Big Data is Driving the Popularity of Predictive Analytics}

Big data is driving the popularity of predictive analytics. Big data by itself is a mass of information that needs to be analyzed. Big data needs predictive analytics to take the data collected and determine the significance of it by combining variables to develop insights that organizations needs for future decision-making (Siegel, 2016). The major inadequacies connected to information handling in a big data environment comprise information overload, information importance, pattern detection, and ambiguity. The unstructured nature of big data such as emails and corporate blogs make choosing relevant data difficult (Bag, 2016). In the last several year's big data has grown substantially. Companies are collecting information on almost everything that can be measured and recorded. However, what businesses do with the data is essential. Analytics technology enables companies to analyze their data and turn it into actionable understandings that can benefit the company (Athow, 2014). Big data has influenced the rise in the popularity of predictive analytics.

Predictive analytics tools are the fundamental enabler of big data, allowing companies to use historical data, combined united with customer insight, to predict future results. Predictive analytics could be anything from managing risk, customer needs, forecasting market trends, resulting in a competitive advantage, and the ability to capture new opportunities and increase profits (Athow, 2014). Predictive analytics recognizes important patterns of data to predict undetermined future events using the discernment of big data and to apply predictive analytics to ambiguous and extremely subjective decisions to model correlations between diverse, relevant elements. The type of big data potentials of volume, velocity, variety, and veracity adds to the creation of big data disparities such as data integrity, identification, aggregation, and confidentiality (Bag, 2016).

\section{Summary}

In this brief paper, we discussed the evolving role of the futurist within the organization. We discussed the history of futurists within the organization for the public and private sectors. We looked at the part of the futurist to determine the relevance of today compared to 20 years ago. We also looked at how the futurist can utilize the futurist's techniques in their organization. 


\section{REFERENCES}

Ag Budin, D. K., \& Wafa, S. A. (2015). The relationship between culture and Leadership style preference among Malay-Brunei, Bajau, and Kadazan-Dusun community in Sabah, Malaysia. Journal of Management Development, 34(10), 1202-1210. doi:10.1108/JMD-02-2015-0019

Amar, A. D., \& Hlupic, V. (2016). Leadership for knowledge organizations. European Journal of Innovation Management, 19(2), 239-260. doi:10.1108/EJIM-12-2014-0120

Anonymous, . (2001). Forecasting techniques for managers. The Futurist, 35(5), 64-65.

Anonymous. (2004). The art of foresight. The Futurist, 38(3), A1-A2, A4-A7.

Asthana, R. (2006). Crossing the analytics chasm. Business Intelligence Journal, 11, 13-21.

Athow, D. (2014). What's driving big data and predictive analytics in 2014? TechRadar.pro. Retrieved from: https:/www.techradar.com/news/internet/data-centre/how-to-master-big-data-and-analytics-in-2014-1211834

Bag, S. (2016). Fuzzy VIKOR approach for selection of big data analyst in procurement management. Journal of Transport and Supply Chain Management, 10(1). Advance online publication. doi:10.4102/jtscm.v10i1.230

Bushe, G. R. P., \& Marshak, R. J. P. (2016). The dialogic mindset: Leading emergent change in a complex world. Organization Development Journal, 34(1), 37-65.

Chong, K. C. (1996). Education for living tomorrow: Premisses for developmental planning. International Journal of Educational Management, 10(4), 10-13. doi:10.1108/09513549610122138

Crews, C. (2017). The right tool for the impossible task. Research Technology Management, 60(6), 48-49. do i:10.1080/08956308.2017.1373051

Fadairo, S., Williams, R., \& Maggio, E. (2015). Using data analytics for oversight and efficiency. Journal of Government Financial Management, 64(2), 18-23.

Faure, M. (2006). Problem Solving Was Never This Easy: Transformational Change Through Appreciative Inquiry. Performance Improvement, 45(9), 22-31, 48. doi:10.1002/pfi.4930450917

Hair, J. F. Jr. (2007). Knowledge creation in marketing: The role of predictive analytics. European Business Review, 19(4), 303-315. doi:10.1108/09555340710760134

Hines, A., \& Gold, J. (2014). An organizational futurist role for integrating foresight into corporations. Technological Forecasting \& Social Change, 101, 99-111. Retrieved from: https://pdfs.semanticscholar.org/29 2f/344fb0ea9f51e2c993d07b5239f840d05908.pdf

Hurtado, P. S., \& Mukherji, A. (2015). Developing a construct of the leader's cognitive flexibility - an interdisciplinary approach. Journal of Competitiveness Studies, 23(1/2), 3-12.

Iovan, S. (2017). Predictive analytics for transportation industry. Journal of Information Systems \& Operations Management, 58-71.

Kerzner, H. (2013). Project Management: A Systems Approach to Planning (11th ed.). Scheduling, and Controlling. Retrieved from https://online.vitalsource.com/\#/books/9781118022276/

Liberatore, M. J., Pollack-Johnson, B., \& Clain, S. H. (2017). Analytics capabilities and the decision to invest in analytics. Journal of Computer Information Systems, 57(4), 364-373. doi:10.1080/08874417.2016.1232995

SAS. (2017). Predictive Analytics. SAS. Retrieved from: https://www.sas.com/en_us/insights/analytics/predictiveanalytics.html\#dmusers

Millett, S. M. (2006). Futuring and visioning: Complementary approaches to strategic decision making. Strategy \& Leadership, 34(3), 43-50. doi:http://dx.doi.org.proxy.cecybrary.com/10.1108/10878570610660591

Millett, S. M. (2011). Five principles of futuring as applied history. The Futurist, 45(5), 39-41.

Mozammel, S., \& Haan, P. (2016). Transformational Leadership and employee engagement in the banking sector in Bangladesh. Journal of Developing Areas, 50(6), 43-55. doi:10.1353/jda.2016.0127 
Northouse, P. G. (2016). Leadership: Theory and Practice (7th ed.). SAGE Publications, Inc.

Prasad, B., \& Junni, P. (2016). CEO transformational and transactional leadership and organizational innovation. Management Decision, 54(7), 1542-1568. doi:10.1108/MD-11-2014-0651

Project Management Institute. (2017). Guide to the project management body of knowledge (PMBOK® Guide) (6th ed.). Project Management Institute.

Ransbotham, S., Kiron, D., \& Prentice, P. K. (2015). Minding the analytics aap. MIT Sloan Management Review, 56(3), 63-68.

Salem, I. E. (2015). Transformational Leadership: Relationship to job stress and job burnout in five-star hotels. Tourism and Hospitality Research, 15(4), 240-253. doi:10.1177/1467358415581445

Shujahat, M., Hussain, S., Javed, S., Malik, M. I., Thurasamy, R., \& Ali, J. (2017). Strategic management model with lens of knowledge management and competitive intelligence. VINE Journal of Information and Knowledge Management Systems, 47(1), 55-93. doi:10.1108/VJIKMS-06-2016-0035

Siegel, E. (2016). Predictive analytics: the power to predict who will click, buy, lie, or die. Wiley.

Smith, D. L. (2015). Evolving Role of the Futurist. Journal of Management Policy and Practice, 16(3), 133-135.

Valikangas, L., Gibbert, M., Nair, L. B., Paukku, M., \& Peixoto, I. (2016). Strategic innovation: the definitive guide to outlier strategies. Pearson Education, Inc.

Webb, A. (2016). The signals are talking. Perseus Books, LLC.

Victor Alan Starns is the Founder/CEO of Pinpoint Consulting and has dedicated his professional focus to organizational and project management for over 30 years. Upon completion of his Bachelors of Science degree and his MBA with summa cum laude honors, Victor was awarded a Doctor of Management degree in project management from the Colorado Technical Institute. Victor started his professional career as a member of Ironworkers Local 24 in Denver. He quickly rose through the ranks to senior leadership positions in project management - planning, overseeing and successfully delivering on the construction of high-rise office building and bridges across the United States. Victor's list of accomplishments range from the General Motors manufacturing plant in Kansas City, Kansas to the highly nuanced construction of the Callaway Nuclear Power Plant in Missouri. Victor is a sought after consultant for his unique combination of Doctoral level project management skill and years of in-the-field project management work cross-industry. Victor is a lifetime member of the National Society of Collegiate Scholars, former Vice President of the Doctoral Student Association at Colorado Technical University and a member of the Project Management Institute. A lifelong learner, Victor values his role as a mentor to encourage others to follow their dreams through hard work and education. He is a native of Colorado and lives in the Denver Metro Area with his wife, Rebecca. 